Journal of Telenursing (JOTING)

Volume 2, Nomor 2, Desember 2020

e-ISSN: 2684-8988

p-ISSN: 2684-8996

DOI: https://doi.org/10.31539/joting.v2i2.1395

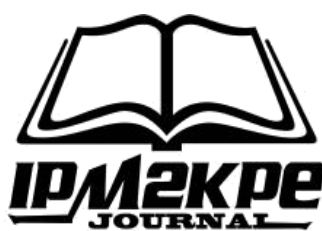

\title{
PEMBELAJARAN CUCI TANGAN TUJUH LANGKAH MELALUI METODE DEMONSTRASI PADA ANAK USIA DINI
}

\author{
Padila $^{1}$, Juli Andri ${ }^{2}$, Harsismanto $\mathrm{J}^{3}$, Muhammad Bagus Andrianto ${ }^{4}$, \\ Rengga Depri Admaja ${ }^{5}$ \\ Universitas Muhammadiyah Bengkulu $1,2,3,4,5$ \\ padila@umb.ac.id ${ }^{1}$
}

\begin{abstract}
ABSTRAK
Penelitian ini bertujuan untuk mengetahui efektivitas metode demonstrasi terhadap kemampuan cuci tangan tujuh langkah pada anak-anak sekolah usia dini di Taman Kanak-Kanak Aisyiyah 1 Kota Bengkulu. Desain penelitian ini menggunakan rancangan pre-eksperimental design dengan one group pretest-posttest. Hasil penelitian menunjukkan bahwa responden sebelum diberikan intervensi yang mendapat kategori bintang I sebanyak 27 orang $(90 \%)$ dan anak mendapatkan kategori bintang II sebanyak 3 orang $(10 \%)$, sedangkan jumlah responden setelah diberikan intervensi mengalami peningkatan kemampuan dan mendapatkan kategori bintang III sebanyak 7 orang $(23,3 \%)$ dan mendapatkan bintang IV sebanyak 23 orang $(76,7 \%)$, dan pada analisa bivariat menggunakan uji wilcoxon diperoleh nilai $p=0,000$. Simpulan, terdapat pengaruh yang signifikan anatara metode demonstrasi terhadap peningkatan kemampuan cuci tangan tujuh langkah pada anak usia dini di Taman Kanak-Kanak Aisyiyah 1 Kota Bengkulu.
\end{abstract}

Kata Kunci: Mencuci Tangan, Metode Demonstrasi, Usia Dini

\begin{abstract}
This study aims to find a website that strives to wash the hands seven of the early childhood school children in Aisyiyah 1 Kindergarten, Bengkulu City. The research design used a pre-experimental method with one group pretest-posttest. The results showed that before the intervention was given the first-star category, there were 27 people (90\%). The children got the second-star sort as many as three people (10\%), while the number of respondents after being given the intervention experienced an increase in ability and the third-star category was seven people ( $23.3 \%)$ and get IV stars as many as 23 people (76.7\%), and the bivariate analysis using the Wilcoxon test obtained p-value $=0.000$. In conclusion, there is a significant influence between the method of increasing the handwashing ability of seven early childhood in Aisyiyah 1 Kindergarten, Bengkulu City.
\end{abstract}

Keywords: Hand washing, Demonstration Method, Early Age 


\section{PENDAHULUAN}

Usia dini merupakan periode emas dimana pertumbuhan dan perkembangan anak terjadi begitu pesat. Pada kategori usia ini anak dituntut untuk melakukan banyak kegiatan yang positif dan setiap kegiatan yang akan dilakukan perlu mendapatkan pengetahuan dan pembelajaran sedari dini agar menentukan aktivitas seorang manusia di masa yang akan datang (Padila et al., 2019). Kategori anak usia dini baik yang berada tingkat pra sekolah, sekolah dasar, sekolah menengah pertama dan sekolah menengah atas merupakan suatu keadaan yang sangat berbeda dengan usia dewasa. Usia ini merupakan masa yang sangat penting bagi pertumbuhan dan perkembangan individu (Padila et al., 2019; Panzilion et al., 2020). Faktor yang mempengaruhi perkembangan anak salah satunya adalah gizi, perawatan kesehatan, kerentanan terhadap penyakit dll (Panzilion et al., 2020). Kebiasaan perilaku hidup bersih dan sehat dikalangan anak usia dini menjadi salah satu prioritas yang harus ditingkatkan, mengingat banyaknya kasus pada anak pra sekolah. Dalam periode ini kebanyakan anak didapatkan sedang mengalami permasalahan kesehatan yang sangat menentukan kualitas anak di masa yang akan datang, salah satu permasalahan kesehatan yang banyak ditemukan pada kategori anak usia dini adalah penyakit diare (Suhenda, 2018).

Diare merupakan salah satu penyakit pembunuh anak nomor dua setelah penyakit Infeksi Saluran Pernafasan Atas (ISPA). Dari hasil riset yang dilakukan oleh Organisasi Kesehatan Dunia (WHO) yang dilakukan pada tahun 2016, angka kematian anak usia dini yang diakibatkan oleh penyakit diare sebanyak 760.000 kejadian pada anak usia dini. Hasil survey yang dilakukan oleh Kementrian Kesehatan RI (2016) menyebutkan bahwa jumlah kejadian kasus diare yang ditemukan di Indonesia berjumlah sekitar 6.897.463 penderita dengan jumlah pasien yang mendapatkan perawatan sebanyak 2.544.084 penderita atau sekitar 36,9 \% dari angka kejadian secara nasional. Faktorfaktor yang menyebabkan kejadian diare pada anak usia dini meliputi beberapa faktor diantaranya akibat perilaku cuci tangan yang salah sebanyak 44,28 \%, akibat faktor lingkungan sebanyak 25,72 \%, akibat keadaan sosial dan faktor ekonomi keluarga sebanyak 9,8 \%, tingkat pendidikan ibu sebanyak 5,2 \%, dan faktor terhadap kategori umur anak sebanyak $15 \%$, sehingga salah satu faktor penyebab angka kejadian diare terbesar yang terjadi pada anak pra sekolah yaitu tidak mencuci tangan sebelum makan (Pratiwi, 2019).

Hal ini juga selaras dalam penelitian Husni (2019) dimana hasil penelitianya menyatakan bahwa, anak usia sekolah juga merupakan masa rawan terserang berbagai penyakit. Kebiasaan anak-anak mengkonsumsi jajanan secara bebas, ditambah anakanak tidak melakukan cuci tangan pakai sabun sebelum makan akan mengakibatkan berbagai penyakit.

Kebiasaan menjaga kebersihan diri dengan mencuci tangan sering dianggap menjadi hal sepele dan kurangnya perhatian oleh masyarakat, padahal kebiasaan mencuci tangan dapat berdampak positif dan bisa memberi kontribusi pada peningkatan status kesehatan baik individu maupun masyarakat. Berdasarkan fenomena yang terjadi di masyarakat terlihat bahwa anak-anak usia dini mempunyai kebiasaan yang buruk terhadap pentingnya menjaga kesehatan dengan mencuci tangan pada kehidupan seharihari, terutama di lingkungan sekolah dan tempat bermain. Kebiasaan yang terjadi pada anak usia dini yaitu langsung memakan makanan yang mereka dapatkan di sekitar sekolah tanpa melakukan kegiatan mencuci tangan terlebih dahulu. Perilaku ini yang tentunya sangat berpengaruh dan dapat memberikan kontribusi yang besar terhadap angka kejadian timbulnya penyakit diare (Rahmadani, 2018). 
Berbagai upaya promotif dan preventif telah dilakukan dalam rangka meningkatkan derajat kesehatan masyarakat dengan penerapan upaya menjaga perilaku kehidupan yang bersih dan menyehatkan. Salah satu indikator dari penerapan Perilaku Hidup Bersih dan Sehat (PHBS) adalah melakukan kegiatan mencuci tangan dengan 7 langkah. Cuci tangan 7 langkah merupakan salah satu upaya dalam tindakan menjaga kesehatan tubuh membersihkan tangan dan jari-jemari menggunakan air dan pemberian sabun untuk menjadikan tangan lebih bersih serta merupakan salah satu cara mencegah dari timbulnya penyakit. Penerapan kebiasaan ini dilakukan bertujuan untuk menjaga kebersihan tangan, karena tangan menjadi salah satu agen yang menyebabkan perpindahan kuman dan patogen dari satu orang ke orang lain, baik dengan kontak langsung ataupun tidak langsung (Itsna, 2018).

Dari permasalahan tersebut peneliti mencoba untuk mengembangkan terkait prosedur dalam mencuci tangan yang semula hanya sepengetahuan anak saja menjadi cara mencuci tangan yang benar menggunakan metode pembelajaran demonstrasi. Pengunaan metode demonstrasi adalah metode yang digunakan oleh seorang guru atau orang luar yang sengaja didatangkan atau murid sekalipun untuk mempertunjukkam gerakan-gerakan suatu proses dengan prosedur yang benar disertai keteranganketerangan (Rahayu, 2018).

Penelitian terkait yang dilakukan oleh Rahayu (2018) hasil penelitian didapatkan hasil bahwa aterdapat pengaruh peningkatan pengetahuan dan sikap pada siswa kelas VII SMPLB Malang setelah diberikan promosi kesehatan melalui metode kombinasi antara ceramah dengan demonstrasi dan latihan.

Penggunaan metode demonstrasi juga pernah diterapkan pada penelitian yang dilakukan oleh Itsna (2018) pada penelitian ini menunjukkan bahwa promosi kesehatan dengan penggunaan metode demonstrasi lebih efektif diakibatkan pemahaman akan hal konkrit lebih mudah dibandingkan dengan hal abstrak dalam meningkatkan pengetahuan dan keterampilan siswa melakukan kebiasaan mencuci tangan.

Penggunaan metode demonstrasi dianggap efektif terhadap pelaksanaan Pendidikan Kesehatan terhadap ketrampilan praktik sadari pada siswi di SMK Batik 2 Surakarta Metode demonstrasi terbukti lebih cocok digunakan untuk mengajarkan praktik Pemeriksaan Payudara Sendiri (SADARI) dikarenakan akan lebih mudah diingat dan dipraktikkan oleh siswi (Hartutik, 2020).

Survey awal yang dilakukan pada 15 januari 2020 di taman kanak-kanak Aisyiyah I kota Bengkulu mengenai perilaku cuci tangan anak, peneliti mendapatkan bahwa anak tidak melakukan cuci tangan setelah bermain dan sebelum melakukan makan bersama. Tahap yang dilakukan adalah hanya mencuci telapak tangan, bagian punggung tangan dan jari tangan. Jika perilaku cuci tangan seperti ini terus dibiarkan, tanpa adanya perbaikan pengetahuan kepada anak-anak, hal ini akan mengakibatkan meningkatnya resiko anak-anak terserang berbagai penyakit.

Telah banyak penelitian terdahulu yang menjelaskan tentang pengaruh cuci tangan pada anak usia sekolah, pada anak sekolah luar biasa tingkat SMP, namun penelitian ini berfokus pada anak usia prasekolah yang sering mengalami diare di Taman KanakKanak.

\section{METODE PENELITIAN}

Metode penelitian ini merupakan metode penelitian kuantitatif menggunakan rancangan pre-eksperimental design dengan one group pretest-posttest. Untuk mengukur pretest dan posttest menggunakan uji statistik non parametric. dimana uji 
wilcoxson digunakan untuk melihat apakah ada pengaruh pretest dan postest pada kelompok intervensi yang diberikan demontrasi cuci tangan tujuh (7) langkah.

Pengambilan Sampel dalam penelitian ini dengan menggunakan kriteria inklusi yaitu anak yang sering mengalami diare 2 bulan terakhir, tidak sedang cedera fisik, berusia 5-6 tahun, dan bersedia menjadi responden, berdasarkan kriteria tersebut didapatkan sampel berjumlah 30 anak dan di intervensi dengan pemberian demontrasi cuci tangan 7 langkah. Penelitian ini dilakukan pada tanggal 26 februari - 26 maret 2020 di TK Aisyiyah 1 kota Bengkulu, Untuk menilai kemampuan cuci tangan digunakan lembar observasi cuci tangan 7 langkah.

HASIL PENELITIAN

Analisa Univariat

Tabel. 1

Distribusi Frekuensi Kemampuan

Cuci Tangan 7 Langkah

\begin{tabular}{cccccc}
\hline No & Kategori & \multicolumn{4}{c}{ Kemampuan Mencuci Tangan } \\
& & Sebelum & Persentase & Sesudah & Persentase \\
\hline 1 & Bintang I & 27 & $90 \%$ & 0 & $0 \%$ \\
2 & Bintang II & 3 & $10 \%$ & 0 & $0 \%$ \\
3 & Bintang III & 0 & $0 \%$ & 7 & $23,3 \%$ \\
4 & Bintang IV & 0 & $0 \%$ & 23 & $76,7 \%$ \\
\hline & Total & 30 & $100 \%$ & 30 & $100 \%$ \\
\hline
\end{tabular}

Sumber: Data Primer yang sudah diolah (2019)

Berdasarkan tabel 1 dari 30 responden pada penelitian ini jumlah responden sebelum diberikan intervensi sebagian besar mendapat kategori bintang I sebanyak 27 orang $(90 \%)$, sedangkan jumlah responden setelah diberikan intervensi sebagian besar mengalami peningkatan kemampuan dan mendapatkan kategori bintang IV berjumlah 23 orang $(76,7 \%)$.

\section{Analisa Bivariat}

Tabel. 2

Hasil Uji Perbedaan Skor Cuci Tangan Sebelum dan Sesudah Metode Demonstrasi pada Anak-Anak

\begin{tabular}{ccccc}
\hline Variabel & Median & Min-Max & Z & P (Value) \\
\hline Metode Demonstrasi (Pretest) & 1 & $1-2$ & $-4,983$ & 0,000 \\
Metode Demonstrasi (Posttest) & 4 & $3-4$ & & \\
\hline
\end{tabular}

Sumber : Data Primer yang sudah diolah (2019)

Berdasarkan tabel 2 didapatkan bahwa nilai tengah skor cuci tangan sesudah diberikan metode demonstrasi lebih tinggi dibanding skor sebelum diberikan intervensi, hal ini berarti terjadi peningkatan skor cuci tangan baik sebelum dan sesudah dilakukan metode demonstrasi. Hasil uji non parametric wilcoxson diperoleh nilai $\mathrm{Z}(-4,983)$ hal ini menunjukan bahwa ada perbedaan antara sebelum perlakuan dan sesudah perlakuan, sedangkan nilai $\mathrm{p}$ value $(0,000)$ hal ini menunjukan bahwa 
nilai $\mathrm{p}$ value $<$ alpha $(0,05)$ yang menunjukkan terdapat pengaruh metode demonstrasi terhadap kemampuan cuci tangan.

\section{PEMBAHASAN}

Berdasarkan tabel 1 Sebelum diberikan metode demonstrasi kepada 30 responden paling banyak berada di dalam kategori bintang I dimana pada katagori ini anak belum mampu mencuci tangan. Setelah diberikan intervensi metode demonstrasi, kemampuan mencuci tangan anak TK Aisyiyah I kota Bengkulu mengalami peningkatan dimana dari 30 responden, 23 orang masuk dalam katagori bintang IV dimana anak sangat mampu mencuci tangan.

Untuk kategori bintang III ada tujuh anak yang mampu mencuci tangan secara mandiri, hal ini dikarenakan setiap anak ke kamar kecil orangtua selalu mendampingi anak dan memfasilitasi anak untuk membawa sabun cair dari rumah sehingga anak termotivasi untuk selalu mencuci tangan secara mandiri dengan menggunakan sabun cair. Dan katagori bintang IV dimana anak sangat mampu mencuci tangan, ketika peneliti tanyakan kepada anak, Jawabanya orangtua mendapat informasi dari peneliti untuk menempel informasi dirumah terkait cara benar cuci tangan, dan itu telah dilakukan orangtua sehingga anak paham betul cara benar mencuci tangan dengan tujuh langkah.

Menurut Silalahi (2019) Salah satu metode pembelajaran yang dianggap tepat untuk diterapkan dalam keterampilan klinis yaitu dengan menggunakan cara demonstrasi terutama untuk anak-anak. Penggunaan teknik demonstrasi adalah suatu penyajian pembelajaran yang dilakukan dengan sangat teliti untuk memperlihatkan sebuah tindakan disertai ilustrasi yang bergerak dan bersuara. Metode demonstrasi adalah suatu metode yang mengajarkan terhadap prosedur dalam suatu proses tindakan adegan dengan mempertimbangkan penggunaan alat peraga yang aman, terjangkau dan efektif untuk dibawa kemana saja.

Berdasarkan tabel 2 Setelah dilakukan uji statistik menggunakan uji non parametrik wilcoxson pada 30 responden terhadap tingkat pengetahuan dan pemahaman terkait pelaksanaan cuci tangan dengan 7 langkah kepada anak usia dini didapatkan bahwa metode demonstrasi efektif terhadap peningkatan kemampuan cuci tangan anak sehingga demonstrasi metode ini, efektif untuk peningkatan kemampuan cuci tangan 7 langkah anak usia pra sekolah.

Penelitian terkait yang dilakukan oleh Rahayu (2018) hasil penelitian didapatkan hasil bahwa aterdapat pengaruh peningkatan pengetahuan dan sikap pada siswa kelas VII SMPLB Malang setelah diberikan promosi kesehatan melalui metode kombinasi antara ceramah dengan demonstrasi dan latihan.

Penggunaan metode demonstrasi juga pernah diterapkan pada penelitian yang dilakukan oleh Itsna (2018) pada penelitian ini menunjukkan bahwa promosi kesehatan dengan penggunaan metode demonstrasi lebih efektif diakibatkan pemahaman akan hal konkrit lebih mudah dibandingkan dengan hal abstrak dalam meningkatkan pengetahuan dan keterampilan siswa melakukan kebiasaan mencuci tangan.

Penggunaan metode demonstrasi dianggap efektif terhadap pelaksanaan Pendidikan Kesehatan terhadap ketrampilan praktik sadari pada siswi di SMK Batik 2 Surakarta Metode demonstrasi terbukti lebih cocok digunakan untuk mengajarkan praktik Pemeriksaan Payudara Sendiri (SADARI) dikarenakan akan lebih mudah diingat dan dipraktikkan oleh siswi (Hartutik, 2020). 
Hal ini sejalan dengan penelitian Nonaita (2019) yang menjelaskan bahwa ratarata peningkatan skor kemampuan menggosok gigi sesudah diberikan metode demonstrasi sebesar 18,60, ini lebih tinggi dibandingkan sesudah diberikan metode film animasi. Maka dapat disimpulkan bahwa ada perbedaan yang signifikan efektivitas metode demonstrasi terhadap kemampuan menggosok gigi pada siswa di SLB Negeri Ungaran Kabupaten Semarang.

Penelitian yang sama juga dilakukan oleh Firmansyah (2018) yang menjelaskan bahwa metode demonstrasi berbasis media cerita lucu bergambar dianggap efektif dalam mempengaruhi peningkatan menulis teks anekdot siswa kelas X SMK Bandung Utara hal ini dikarenakan penerapan mekanisme demonstrasi menjadi hal yang sangat penting (contextual teaching and learning) pada saat melakukan pembelajaran dikarenakan bahwa dalam proses pembelajaran pendemonstrasi sangat diperlukan perannya. Demonstrasi yang dilaksanakan merupakan salah satu wujud dari proses pemodelan (modeling) yang dilakukan pendidik dengan tujuan agar peserta didik mendapatkan gambaran secara kongkret aktivitas yang dicontohkan.

Penelitian oleh Manurung (2020) membuktikan bahwa perilaku cuci tangan dapat mencegah kejadian diare, mengurangi risiko flu burung, pneumonia, dan sebagai indikator keberhasilan PHBS. Mencuci tangan sangat efektif untuk mencegah penyakitpenyakit tersebut dan mengurangi risiko penularan penyakit pada anak-anak lima tahun kebawah hingga $45 \%$ yang disebabkan karena perpindahan bakteri dan keadaan tangan yang terlihat kotor pada saat mengkonsumsi makanan.

\section{SIMPULAN}

Metode demonstrasi sangat efektif terhadap peningkatan kemampuan cuci tangan tujuh langkah pada anak usia dini yang berada pada TK Aisyiyah 1 Kota Bengkulu.

\section{SARAN}

Bagi orang tua yang memiliki anak dengan usia pra sekolah (5-6 tahun) untuk dapat membentuk kemandirian pada anak, diharapkan agar lebih meningkatkan sikap positif dalam memberikan pengetahuan dan memberikan pengajaran secara tepat kepada anaknya dan juga memberikan semangat serta dorongan kepada anaknya agar menggali potensi dan kemampuan diri dengan memberikan banyak kegiatan yang positif agar anak dapat belajar mandiri khususnya dalam hal personal hygiene (mencuci tangan) sehingga kebersihan anak terjaga, kebersihan yang terjaga memungkinkan anak untuk bersosialisasi dengan baik bersama orang lain, kesehatan anak juga bisa terjaga dengan baik, dengan demikian anak dapat tumbuh dan berkembang secara optimal.

\section{DAFTAR PUSTAKA}

Firmansyah, F., Firmansyah, D., Cibaduyut, S. B. U., \& Siliwangi, I. K. I. P. (2018). Penerapan Metode Demonstrasi Berbasis Media Cerita Lucu Bergambar dalam Pembelajaran Menulis Teks Anekdot pada Siswa. Parole (Jurnal Pendidikan Bahasa dan Sastra Indonesia), 1(4), 585-590

Hartutik, S. (2020). Efektifitas Pendidikan Kesehatan Media Audio Visual (Video) dan Demonstrasi terhadap Ketrampilan Praktik Sadari. IJMS-Indonesian Journal on Medical Science, 7(1) 
Husni, E., \& Ramadany, S. (2019). Praktek Cuci Tangan Pake Sabun pada Siswa Sekolah Dasar 05 Nagari Mungka Kabupaten 50 Kota. Jurnal: Buletin Ilmiah Nagari Membangun. 2(4). http://buletinnagari.lppm. unand.ac.id/ index.php/bln/ article /view/153

Itsna, I. N., Hapsari, W., \& Indrastuti, A. (2018). Efektifitas Pendidikan Kesehatan Cuci Tangan Pakai Sabun (Ctps) dengan Metode Demonstrasi dan Booklet pada Siswa Kelas VI SDN Kalisapu 04 Slawi. Bhamada: Jurnal Ilmu dan Teknologi Kesehatan (E-Journal), 9(1), 8-8

Manurung, I. F. E. (2020). Peningkatan Pengetahuan dan Praktek Cuci Tangan Sebagai Upaya Pencegahan Penyakit Diare pada Anak Sekolah Dasar Marsudirini Kefamenanu. Warta Pengabdian, 14(2), 134-140

Nonaita, Y. U. V. E. (2019). Perbedaan Efektifitas Metode Demonstrasi dan Film Animasi terhadap Kemampuan Menggosok Gigi pada Siswa-Siswi di Slb Negeri Ungaran. Universitas Ngudi Waluyo

Panzilion, P., Padila, P., Amin, M., \& Andri, J. (2020). Perkembangan Motorik Prasekolah antara Intervensi Brain Gym dengan Puzzle. Jurnal Keperawatan Silampari, 3(2), 510-519. https://doi.org/https://doi.org/10.31539/jks.v3i2.1120

Panzilion, P., Padila, P., Setyawati, A. D., Harsismanto, J., \& Sartika, A. (2020). Stimulation of Preschool Motor Development Through Brain Gym and Puzzle. JOSING: Journal of Nursing and Health, 1(1), 10-17. https://doi.org/https://doi.org/10.31539/josing.v1i1.1166

Padila, P., Andari, F. N., \& Andri, J. (2019). Hasil Skrining Perkembangan Anak Usia Toddler antara DDST dengan SDIDTK. Jurnal Keperawatan Silampari, 3(1), 244-256. https://doi.org/10.31539/jks.v3i1.809

Padila, P., Andari, F. N., Harsismanto, J., \& Andri, J. (2019). Tumbuh Kembang Anak Usia Toddler Berbasis Research. Lubuklinggau: Asra

Pratiwi, O. F. (2019). Hubungan Perilaku Cuci Tangan dengan Kejadian Diare pada Anak Balita di Tb-Kb-Tkit Salman Alfarisi Kecamatan Umbulharjo Kota Yogyakarta. Universitas' Aisyiyah Yogyakarta

Rahayu, P., \& Ummah, U. S. (2018). Metode Demonstrasi Mencuci Tangan Anak Tunagrahita Ringan. Jurnal Ortopedagogia, 2(1), 26-29

Rahmadhani, S. (2018). Pengaruh Promosi Kesehatan dengan Metode Story Telling Audio Visual terhadap Kemampuan Cuci Tangan 6 Langkah pada Anak Usia Pra Sekolah di PAUD Khalifah Muara Gondang Tahun. STIKes Perintis Padang

Silalahi, S. S. (2019). Efektivitas Metode Demonstrasi dan Media Video tentang Pemeriksaan Tanda-Tanda Vital terhadap Kemampuan Keterampilan Klinis Mahasiswa Keperawatan Universitas Sumatera Utara. Universitas Sumatera Utara

Suhenda, A., Rohmana, O., \& Santoso, A. B. (2018). Efektifitas Pendidikan Kesehatan antara Metode Ceramah dan Demonstrasi terhadap Peningkatan Pengetahuan Cuci Tangan Siswa SDN Sunyaragi Kota Cirebon. Jurnal Persada Husada Indonesia, 5(18), 70-75 